Research, part of a Special Feature on Catastrophic Thresholds, Perspectives, Definitions, and Applications

\title{
Grasshopper Population Ecology: Catastrophe, Criticality, and Critique
}

\author{
$\underline{\text { Dale R. Lockwood }}^{1}$ and Jeffrey A. Lockwood ${ }^{2}$
}

\begin{abstract}
Grasshopper population dynamics are an important part of the North American rangeland ecosystem and an important factor in the economies that derive from the rangeland. Outbreak dynamics have plagued management strategies in the rangeland, and attempts to find simple, linear and mechanistic solutions to both understanding and predicting the dynamics have proved fruitless. These efforts to ground theory in a correspondence with the "real" world, including whether the population dynamics are ultimately density dependent or density independent, have generated abundant heat but little light. We suggest that a pragmatic approach, in which theories are taken to be "tools" rather than competing claims of truth, has greater promise to move ecological research in a constructive direction. Two recent non-linear approaches exploiting the tools of complexity science provide insights relevant to explaining and forecasting population dynamics. Observation and data collection were used to structure models derived from catastrophe theory and self-organized criticality. These models indicate that nonlinear processes are important in the dynamics of the outbreaks. And the conceptual structures of these approaches provide clear, albeit constrained or contingent, implications for pest managers. We show that, although these two frameworks, catastrophe theory and self-organized criticality, are very different, the frequency distributions of time series from both systems result in power law relationships. Further, we show that a simple lattice-based model, similar to SOC but structured on the biology of the grasshoppers gives a spatial time series similar to data over a 50year span and the frequency distribution is also a power law relationship. This demonstration exemplifies how a "both-and" rather than an "either-or" approach to ecological modeling, in which the useful elements of particular theories or conceptual structures are extracted, may provide a way forward in addressing particularly difficult ecological problems.
\end{abstract}

Key Words: catastrophe theory; complexity science; grasshoppers; models; pest management; population dynamics; rangeland ecosystem; self-organized criticality

\section{INTRODUCTION}

Understanding population ecology and making predictions about population dynamics would be sufficiently challenging based only on the complicating qualities that living entities bring to the problem (variation and history), but an ecologist must also taken into consideration the particularities of a given system. In our case, grasshopper (Orthoptera; Acrididae) populations in the western United States are the focus of interest, and these systems have a number of features that are relevant to the inquiry. The fact that some of these qualities are of pragmatic concern makes them no less real for the scientist and no less important for the ecologist.
Grasshoppers cause serious economic damage to both crops and rangeland, although the greatest concern has been with respect to losses of livestock forage in the latter system (Hewitt and Onsager 1983, Joern and Gaines 1990). Grasshoppers annually consume $>20 \%$ of rangeland forages in the western United States at an estimated loss of \$400 million (Hewitt and Onsager 1983), and during the last major grasshopper outbreak, $>8$ million ha of rangeland were treated with 5 million liters of malathion at a cost of $\$ 75$ million (Lockwood et al. 2002).

Advances in rangeland grasshopper management have been made in the last decade. What is lacking, however, is any substantive advance with regard to 
state and federal forecasting of rangeland grasshopper population dynamics that would allow limited resources to be acquired, allocated, and applied in an optimal manner.

Pest management systems are as reactive-and no more proactive-than they were 25 years ago. Crude, ground-based surveys are still the mainstay for generating maps based on a current year's infestations, and these maps serve as the only tool for "predicting" future dynamics under the assumption that whatever conditions prevail in the present are a plausible forecast of the following year. However, such forecast maps have proven notoriously unreliable, as infestations disappear without human intervention and others arise from lands with no evidence of infestation in the previous year (Lockwood and Schell 1995). As such, the population ecology of rangeland grasshoppers remains perhaps the weakest link in a network of pest management systems that encompass millions of square kilometers of grasslands.

Given the extensive and heterogeneous qualities of rangeland habitats that grasshoppers may infest, the enormous range of ecological and biological qualities that these insects exhibit, and the spectrum of human concerns that define and constrain scientific investigation (e.g., the goals of protecting endangered and non-target species, conserving economically beneficial processes, and protecting socioeconomically valuable resources), we suggest that a single, universal approach to population dynamics is extremely unlikely to produce valuable insights or useful forecasts. Perhaps there is some universal equation that captures the fundamental processes of population growth and decline, but the ecological, economic, and political contingencies of pest management in semi-natural settings strongly suggests that a pluralistic approach to modeling is defensible. As such, the driving question should not be, "What is the objectively right model for grasshopper population dynamics?" but "Under what conditions is a particular model useful for grasshopper population management?" This pragmatic, "toolbox" approach has led us through a series of investigations that have provided analytical methods with the potential of providing a basis for understanding and forecasting grasshopper population dynamics while revealing the limits of, or contingencies within, various conceptual and mathematical frameworks. This paper builds on and integrates established models of grasshopper population dynamics based on catastrophe theory and self-organized criticality (SOC) (Lockwood and Lockwood 1989, 1991, 1997).

\section{BIOLOGY OF GRASSHOPPERS}

Taxonomic diversity is one of the greatest challenges with regard to developing population models of rangeland grasshoppers. In the western United States, the family Acrididae includes four subfamilies: Gomphocerinae, Melanoplinae, Oedipodinae, and Romaleinae. Each of these taxa has general tendencies that would make treating the entire family as a single, ecological entity problematic (e. g., gomphocerines are almost all gramnivores, whereas melanoplinae are most often forbivores). Moreover, differences among species within subfamilies may be profound (e.g., Melanoplus sanguinipes flies long distances, consumes dozens of forbs and grasses, and can produce 400 eggs/ female, whereas Hypochlora alba is flightless, feeds only on Artemisia, and produces 40 eggs/female; Pfadt 2002). This diversity is particularly problematical considering that all long-term data sets for rangeland grasshoppers lump the species into a single taxonomic grouping. There are more than 400 species of acridids on western grasslands and shrublands (Capinera et al. 2005), with 113 species documented in Wyoming, where the most comprehensive faunal surveys have been conducted (Schell and Latchininsky 2006). So, let us briefly consider the biological parameters that may be most important to understanding the constraints of grasshopper population models (where "grasshopper population" is taken to mean, by virtue of the available data, the assemblage of all acridid species).

Rangeland grasshoppers range from the nearly monophagous (e.g., Melanoplus bowditchi feeds almost exclusively on silver and sand sagebrush) to the extraordinarily polyphagous (Melanoplus bivittatus feeds on a remarkable diversity of grasses, cereals, mustards, legumes, and composites) (Chapman 1990, Pfadt 2002). Perhaps 10 to 15 species comprise the major rangeland pests, capable of reaching high densities and feeding on economically valuable plants (Capinera and Sechrist 1982, Pfadt 2002). However, there are also some economically beneficial species that feed on noxious weeds (e.g., Hesperotettix viridus preferentially consumes snakeweed, a plant poisonous to livestock). 
With respect to reproduction, most rangeland grasshoppers are univoltine, although a few species may produce two generations per year in warmer habitats and years, and some alpine species require 2 years to complete a single generation (Pfadt 2002). Depending on the species, grasshoppers oviposit clusters of three to 200 eggs in the soil, with a female producing from one to six pods. The eggs typically overwinter (diapause) in the soil, although a few species hatch in late August and the nymphs overwinter. Hatching takes place from early May to mid August (the hatching window for any particular species being 2 to 4 weeks). After hatching, a grasshopper nymph passes through four to five instars, with each stage lasting 4 to 7 days, depending on the species and the temperature. Adult females typically have a 1 - to 2 -week preoviposition period, during which they mate, and eggs develop internally.

The movement of grasshoppers is a function of both walking, hopping, and flight. Mark-recapture studies suggest that movement of late-instar nymphs and young adults yields a net displacement of 3-5 $\mathrm{m} / \mathrm{d}$, with a tendency for individuals to move in an upwind direction (Narisu et al. 1999). However, some species move much longer distances, particularly when they are in crowded conditions. This density-movement relationship is most pronounced in the Old World locusts, although some North American grasshoppers, such as $M$. sanguinipes, also form swarms that can travel 50 to $100 \mathrm{~km} / \mathrm{d}$ (Pfadt 2002).

In all life stages, rangeland grasshoppers are subject to a wide variety of predators (primarily insects, mammals, and birds), parasites (coleopteran, hymenopteran, and dipteran parasitoids, as well as nematodes), and pathogens (principally viruses, fungi, and protozoa; the extent to which diseases affect the egg stage is uncertain). Survivorship is a function of temperature, such that the slower the development of the grasshoppers before reproduction, the greater the mortality suffered by that particular generation. Direct effects of abiotic factors on grasshopper survival are also important, with lethally cold conditions reducing populations in the spring and fall, and heavy rains killing young nymphs. Interactions between biotic and abiotic factors may be most important in terms of grasshopper mortality (Lockwood 1990a). For example, in a wet spring, nymphs may have a difficult time consuming enough nutrients from water-laden plant tissues, heavy rains can physically damage the immature grasshoppers, and fungal pathogens are favored when relative humidity is high (Streett and McGuire 1990). Population density of rangeland grasshoppers is often fewer than three individuals per $\mathrm{m}^{2}$, but during an outbreak, densities of $20-50 / \mathrm{m}^{2}$ across tens of thousands of hectares are common (Schell and Latchininsky 2006).

The density and diversity of grasshoppers within an area is a function of the topography, soil, and vegetation (Kemp et al. 1990, Schell and Lockwood 1997). It is not unusual to find 15 to 30 species within a hectare of rangeland, although an assemblage often has one or two species comprising one- to twothirds of the individuals. These dominant species are most often pests, and it appears that reproduction of other, less common species effectively coat-tails on the saturation of predators that comes with high densities of the primary species.

One means of summarizing the complexity of rangeland grasshopper ecology is to attempt to construct a food web based on the best available information concerning trophic relationships. Our efforts to formulate such a framework (Fig. 1) illustrate the absurdity of attempting to develop a population model of these insects based on a simple mechanistic approach. Clearly, a differential equation model of rangeland grasshopper population dynamics would be an exercise in reductionistic frustration. As we pointed out in our earlier work, assuming that there are 30 grasshopper species in one of seven developmental stages (eggs, five nymphal instars, and adults) that interact with 40 different predators, parasites, and pathogens, and live on rangeland vegetated by 30 plant species, there are more than 20000 direct relationships affecting the system, and more than a billion indirect relationships (many of which play significant roles; Joern and Gaines 1990). If only $1 \%$ of the direct interactions are mechanistically important, ecologists would need to develop and parameterize 200 mathematical expressions.

\section{CONVENTIONAL SOLUTIONS TO THE PROBLEM OF POPULATION DYNAMICS}

Rangeland grasshoppers exhibit "boom and bust" or outbreak dynamics. In any one year, the population of nymphs and adults may be orders of magnitude larger than the previous year's values, 
Fig. 1. The food web of 58 species of rangeland grasshoppers in Wyoming. Each node represents a single species or a set of closely related species. The yellow represents grasshoppers, blue represents birds, tan represents mammals, purple represents pathogens, pink represents insects, nematodes, and spiders (parasites, parasitoids, and predators), red represents hyperparasites, and green represents plants. Gray nodes represent non-living material including leaf litter, dung, and dead arthropods. Although the food web is a directed graph, we omit the arrows signifying direction in the figure due to the density of edges. Note that there are loops present in the figure where cannibalism occurs (which is distiguished from necrophagy, represented in the gray nodes). This food web is necessarily incomplete as only links found in primary literature have been included (Peterson 1955, Lavigne and Pfadt 1966, Banfield 1974, Bekoff 1977, Ritchie 1978, LaChapelle et al. 1984, Pierce and Peek 1984, Arjo and Pletscher 1999, Pfadt 2002).

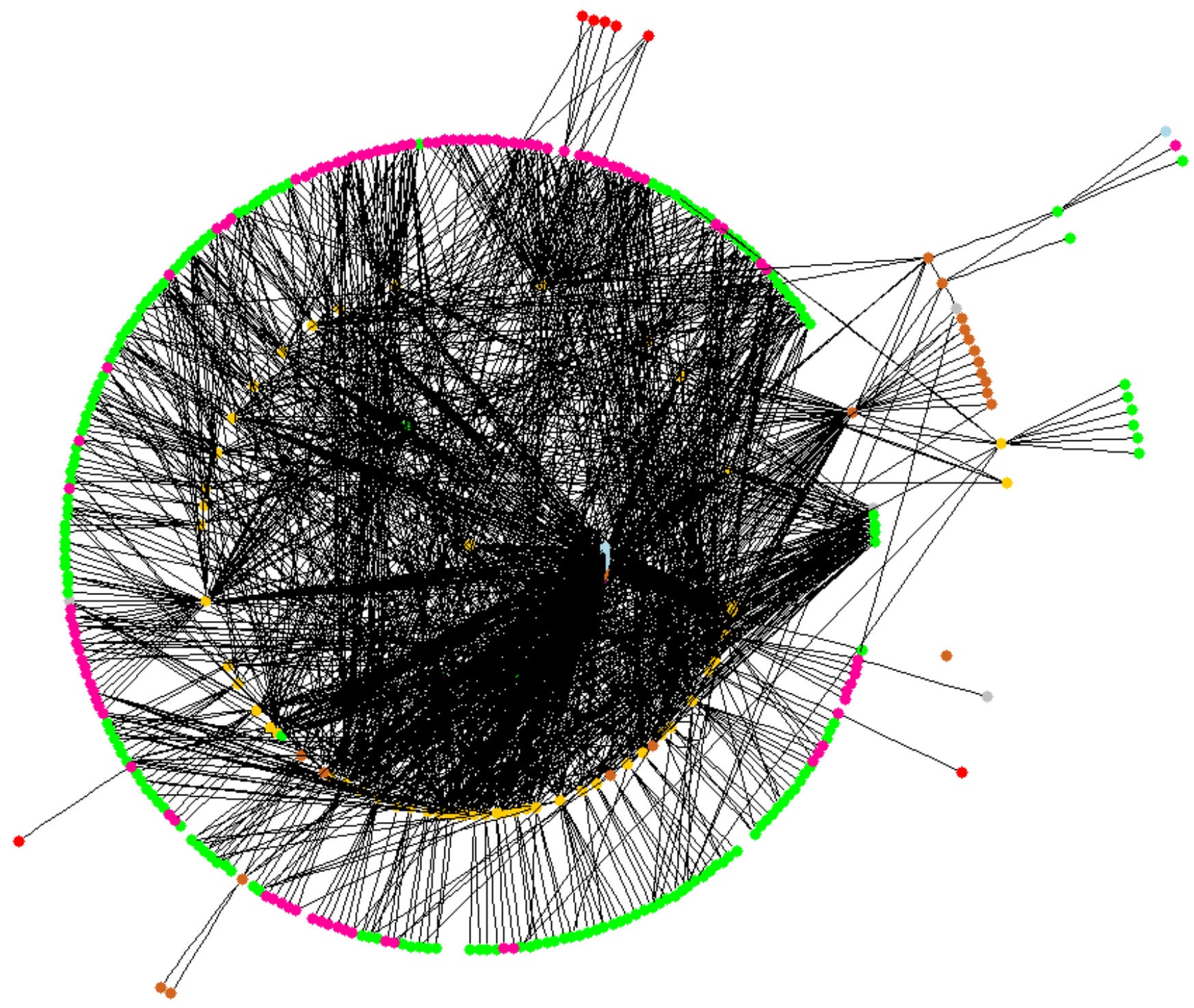


and in the following year, the population may crash with very few individuals remaining. Rangeland grasshopper outbreaks are highly structured with respect to space, exhibiting many small outbreaks and a few large-scale infestations (see supplemental material). These outbreaks occur at different locations from one year to the next, although a few locations see repeated and prolonged outbreaks.

The theory of population dynamics is largely focused on the regulation of population densities. A dichotomy has existed for years regarding the nature of the control on populations with densityindependent and density-dependent processes each being championed. Recently it has been argued that density dependence is the only means for population regulation (Turchin 1995). The general model proposed by Turchin is of the form,

$$
r_{t}=f\left(N_{t-1}, N_{t-2}, \ldots\right)+\varepsilon_{t}
$$

where $r_{t}$ is the per capita growth rate and $f$ is a function of the population at one or more previous generations (explicitly accounting for lags) and all density-independent effects are treated as additive and independently distributed normal random variables. However, it is not clear that the densityindependent effects can be segregated into a single term and are not intrinsically coupled to the function $f$ as controlling the parameters of the function (e.g., a density-independent effect such as rainfall may foster fungal disease, the spread of which is density dependent). In addition, evidence suggests that the normalcy assumptions about environmental effects are not supported by data (Mandelbrot and Wallis 1969, Vattay and Harnos 1994, Pelletier 1997) and that there are serious potential consequences for assuming a normal distribution for environmental effects (Cuddington and Yodzis 1999, Morales 1999). That density-dependent processes can produce stable equilibria, cycles, and chaos does not imply that the variability in populations is caused predominantly by density-dependent functions (Hall 1988).

Philosophically, there seems little wrong with considering the absolute limit on a population to be a function of its density, yet there is no reason why density-independent processes cannot limit populations as well. Such factors could, in principle, keep a population from ever reaching the point at which density-dependent regulation is relevant. In fact, various studies can account for significant densityindependent factors in populations of insect species (Andrewartha and Birch 1954, Price and Clancy 1986, Swetnam and Lynch 1993, Ylioja et al 1999).

Berryman (1987) provides a simple structure for defining outbreaks and provides a simple model of the dynamics of populations based on the logistic equation. His equation is a variation of the general form discussed by Turchin (1995) with the absence of a noise term. This equation can result in simple equilibrium dynamics, periodic cycling, or chaos in discrete form. In the continuous form, it results in generally simple equilibrium dynamics. The model is extended to include a third-order population term that results in two stable equilibria and an unstable equilibrium. This form is very similar to the model presented by Lockwood and Lockwood (1989, 1991). As the parameters of the expression vary, the population can shift from a bistable system to a single equilibrium with the equilibrium value determined by the parametric values.

Experimental models generally focus on densitydependent factors. For example, Belovsky and Slade (1995) created an artificial environment for two species of grasshoppers and monitored the population densities. The experimental setup included high densities of $M$. sanguinipes and $M$. femurrubrum in cages with a basal area of $0.1 \mathrm{~m}^{2}$. These cages, of course, excluded all large predators and most other arthropod predators, parasites, and competitors. They also artificially constricted the behavior of the grasshoppers, as both species are long-distance dispersers. Under such conditions, density dependence via food limitation was found. It remains an open question as to whether the numerous factors excluded from the study play a more significant role in regulating the population dynamics on scales that are more realistic for individuals and populations.

Other studies demonstrate a link between populations of grasshoppers and exogenous factors. In North American rangelands, weather has been shown to be important to population regulation of grasshoppers (Capinera and Horton 1989, Fielding and Brusven 1990, Skinner and Child 2000). Similar results are shown for grasshopper populations on the Indian subcontinent (Karpakakunjaram et al. 
2002). In each of these instances, weather, principally precipitation and temperature, appears as an important factor in the regulation of populations of grasshoppers, but no causal mechanism or model of the relationship is presented. Similarly, Branson (2005) showed a relationship between fire and population densities, and suggests that more work is required to determine a mechanism. Gage and Mukerji (1976) constructed a model based on the thermal requirements for egg and nymph development, which suggests that temperature plays a significant role in development. Thus, temperature will influence the reproductive success of each generation.

\section{UNCONVENTIONAL SOLUTIONS TO THE PROBLEM OF POPULATION DYNAMICS}

Perhaps the clearest ecological relationship between grasshoppers and the rest of the natural world is that weather, through direct and indirect processes, affects population dynamics in a reliable manner that is not adequately captured in linear models (Edwards 1960, 1962, Gage and Mukerji 1977, Watts et al. 1982, Lockwood 1990b). In large part, the analytical shortcomings were probably due to the difficulty of using continuous models to reflect $>10$-fold increases in the densities and areas of infestation in sequential years. We have explored whether catastrophe theory would provide a useful, non-mechanistic method for understanding a system whose inner workings are poorly known (Lockwood and Lockwood 1991).

Catastrophe theory is a framework for the study of discontinuous phenomena in normally continuous systems (Thom 1972, Gilmore 1981), so its relevance to grasshopper population dynamics was readily apparent. Other researchers have used catastrophe theory in certain ecosystems to describe sudden responses of a population or other state variable to slow environmental changes. This is a perfectly valid use of catastrophe theory (although it is more a case of bifurcation theory), but the mathematics of catastrophe theory do not require time dependence in the state variable transitions. Rather, it is a topological relationship between the control and state parameters, as described by the manifold.

The cusp catastrophe (Fig. 2), which is the stable manifold of a state variable that arises from two driving or control parameters (bimonthly temperature and precipitation in our model), yielded results that were qualitatively and quantitatively consistent with 28 years of grasshopper population dynamics in four ecoregions of Wyoming. A validation procedure using data withheld from the model during development, demonstrated that a cusp catastrophe predicted rangeland grasshopper population outbreaks and crashes at a rate significantly better than chance. For example, in Wyoming's Platte Valley, the model predicted areas of infestation within 8000 ha of those that actually occurred from 1988 to 1990 . The best fit was found with a model based on April-May weather (during which many of the pest grasshopper species are undergoing hatching and early development) used to predict large-scale (30\% to $45 \%$ increase in the total area of infestation within a region), highdensity (>10 grasshoppers $/ \mathrm{m}^{2}$ ) outbreaks in the most frequently infested regions. However, the model was much less reliable for population crashes and relatively small-scale dynamics $(15 \%$ changes in the area of infestation from one year to the next) of low population densities (four to 10 grasshoppers $/ \mathrm{m}^{2}$ ) in regions with less frequent outbreaks.

With respect to the question of "Under what conditions is a particular model useful for grasshopper population management?" we can say that the cusp catastrophe model showed promise for predicting substantial changes of high population densities at large spatial scales (each ecoregion was at least $12000 \mathrm{~km}^{2}$ ). The non-mechanistic approach to using temperature and precipitation in the model allowed a mathematically rigorous approach to what are widely regarded as critical, but intractably complex, factors. However, in our effort to discover conceptually manageable and practically useful approaches to understanding and predicting grasshopper population dynamics, we sought a yet simpler, if even more unconventional, analytical framework.

Self-organized criticality is manifest in systems consisting of a substrate that can be locally stressed such that the resulting release shifts the stress to neighboring locations, which, in turn, propagate the disturbance. Our previous analyses of 40 to 50 years of grasshopper population dynamics in Idaho and Wyoming have revealed the diagnostic features of SOC (Lockwood and Lockwood 1997). That is, ecoregions in both of the states had frequency distributions of areas infested with grasshoppers that yielded a statistically significant fit to a power 
Fig. 2. The surface represents the equilibrium manifold of the cusp catastrophe. The path marked in red demonstrates the hysteresis, sudden jump and bimodality properties of the cusp. The blue paths represent the divergence property.

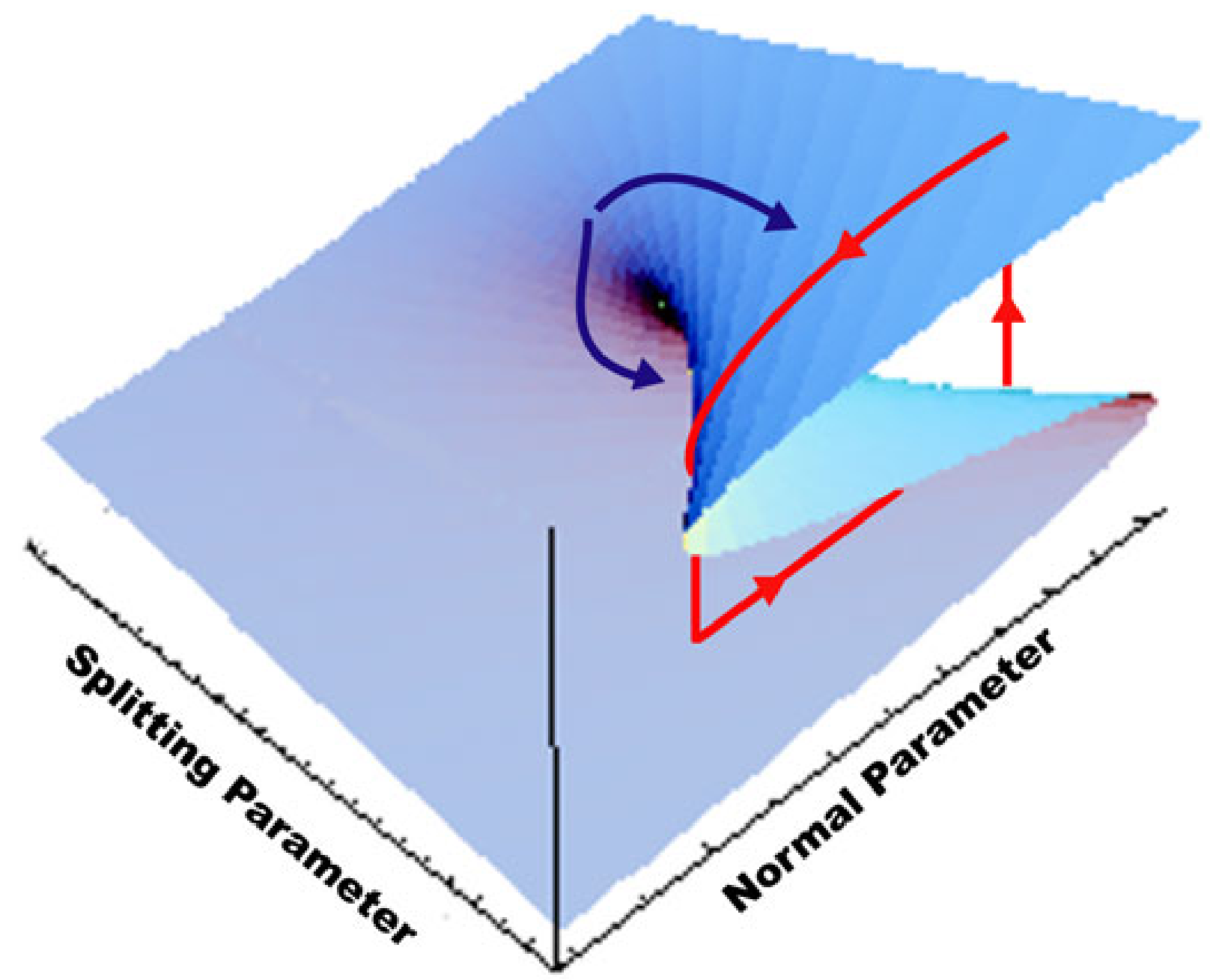

law. This evidence of $1 / f$ noise complemented the discovery of fractal behavior. Spatial self-similarity was evident from statistically significant correlations among areas of infestation.

The relevance of this study of large-scale, long-term dynamics to understanding and managing grasshopper population dynamics was compelling.
Outbreaks and crashes may be structural elements of the system, such that grasshopper populations are not just passively responding to external forcing but self-structuring such that what appear to be small changes in weather (or predators, food, etc.) can produce large changes in the population. Because SOC reveals only the overall behavior of system, it cannot be used to forecast the size or location of a 
particular event. To predict the next outbreak dynamic in a SOC system, the entire system must be perfectly mapped and the location of the disturbance must be precisely known. Without this knowledge, it is impossible to predict the size of the outbreak.

If grasshopper populations exhibit SOC, there are a number of potentially profound ecological and management implications (Lockwood and Lockwood 1997). The first concern pertains to the common perception among those responsible for agricultural policies pertaining to pest managers that weather and other external events are essential to inducing outbreaks. Although our work suggests that such perturbations can trigger critical events, grasshopper populations - and perhaps many other aspects of the ecological world-do not fit into "simple complexity." Rather, the population dynamics of these insects are consistent with the existence of interacting complex systems (the chaotic forces of weather superimposed on a population exhibiting SOC).

Second, policy makers in search of monistic explanations of complex pest systems may be frustrated by the evident lack of a singular mechanism to account for population dynamics. Although there may be external forcing of outbreaks or crashes, the grasshopper community may integrate internal and external processes. Taken in theoretical isolation, SOC systems may be relatively insensitive with respect to the temporal pattern of external noise. However, externalities in the real world may alter the qualitative behavior of the system, such that a system with underlying SOC could well exhibit other dynamics by virtue of such events (e.g., large-scale insecticide treatments of grasshopper populations or the introduction of nonnative predators, parasites, or pathogens into the system).

Third, policy makers may be tempted to dismiss the discovery that grasshopper population exhibited SOC, given that this process does not provide forecasts but only reflects the qualitative behavior of the system. Although specific predictions are not possible, SOC has potentially powerful implications for pest management practices. In systems exhibiting SOC, attempts to stop a critical event (e. g., a grasshopper outbreak) result in spatiotemporal dislocation. That is to say, the event is shifted to some other place and time. The bottom line for the policy maker is that the global power law is unchanged by "management."
Returning to our question of "Under what conditions is a particular model useful for grasshopper population management?" we can say that SOC is scale invariant in a spatial context but uninformative with regard to any particular temporal scale. That is, we know the size structure (power law distribution) of rangeland grasshopper outbreaks, but we cannot predict the dynamics at a future time. So this model is valuable for pest managers (and the agencies that fund them) in understanding that the allocation of resources should reflect the underlying pattern of grasshopper population dynamics. That is, the historical pattern of disassembling programs and expertise after major outbreaks in the expectation that "the problem is solved" and the infrastructure is no longer needed is utterly mistaken, for although the area of infestation will be small in most years, large and rapidly developing outbreaks are fundamental to the system.

\section{TWO COMPLEXITIES AND ONE SYSTEM}

Both of the unconventional approaches outlined in the previous section involve nonlinear dynamics, but the underlying structures of the two systems are very different. Catastrophe theory is a low dimensional system with a strong exogenous control of the state variable, whereas SOC is a high dimensional system with a weak exogenous factor and a strong endogenous process. Catastrophe theory is not spatial in its formulation, whereas SOC is explicitly spatial. The question this raises is: How do two very different mathematical approaches both accurately capture the complex dynamics of grasshopper populations? We show that the cusp bifurcation can produce dynamics that are generally attributed to SOC-type systems, which leads to difficulties in determining the underlying mechanisms.

The cusp bifurcation is structured with two control parameters whose values exogenously determine the equilibrium of the state variable. For different values of the control parameters, the state variable may take on one or two stable equilibria (Fig. 2). SOC dynamics are largely determined endogenously by the configuration of the number of units arranged on the lattice. SOC gives rise to power-law distributions of cascades or outbreaks (Fig. 3A) as well as fractal self-similarity in space.

A uniform random walk in the control parameters of a cusp bifurcation results in a frequency 
Fig. 3. These diagrams represent: A) the frequency distribution of the standard two-dimensional sandpile model1, for 100000 iterations. B) the distribution of the change in the state variable for a uniform random walk for the two control parameters. C) the same process as in (B) but with the scale of observation set two orders of magnitude lower.

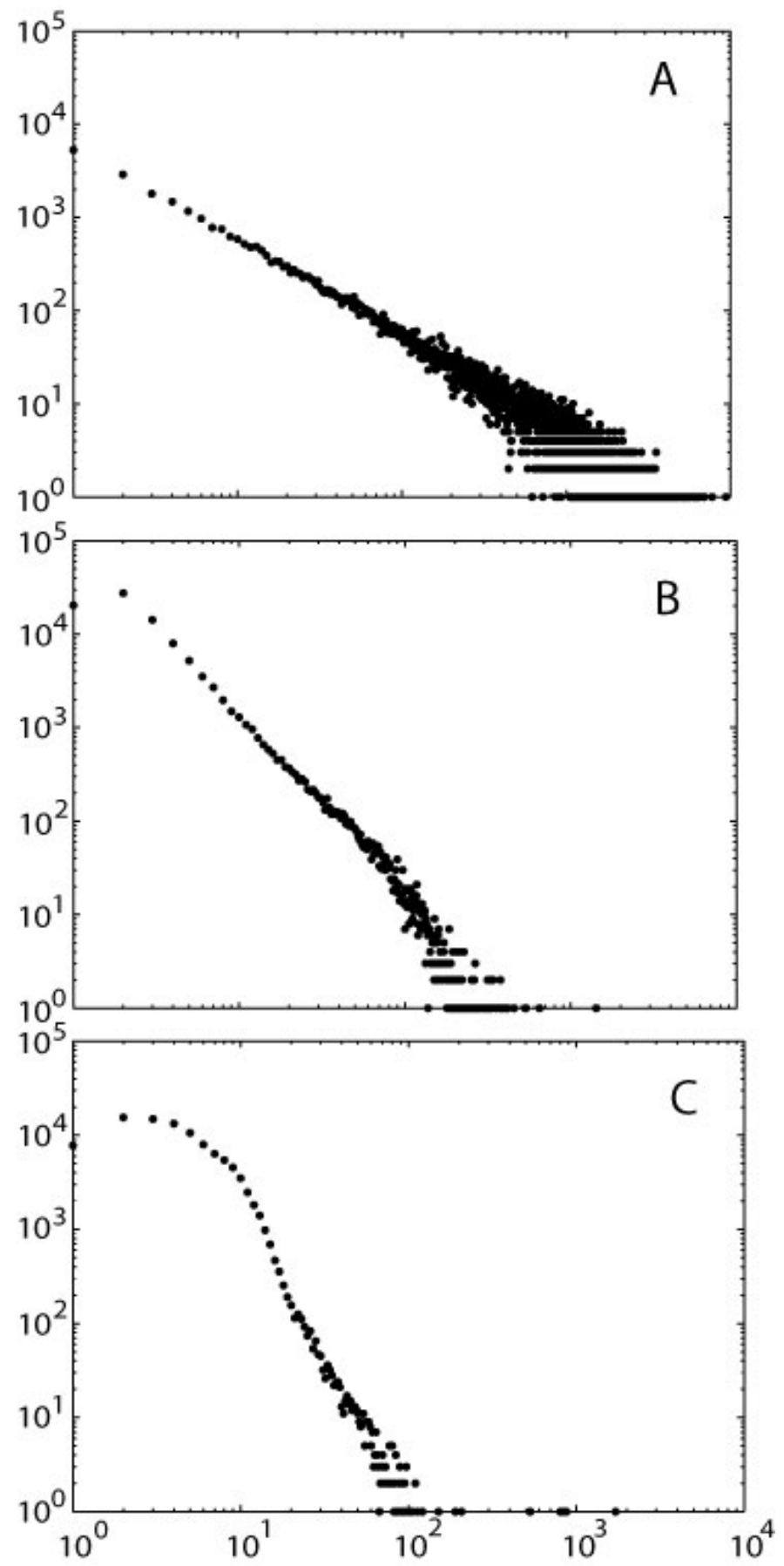


distribution with a power-law shape (Fig. 3B). Note that the smallest scale of change is lower in frequency. Modification of the step size of the random walk creates a "hockey stick" type distribution (Fig. 3C).

The tail of the distribution, viewed in log-log space, is likely more important than the rather flat distribution for the very small changes in the state variable. Sampling of data over long time series in ecological systems does not produce large data sets. To analyze the frequency distribution of the series, the data must be binned. This binning will collapse the small change categories together, resulting in a heightening of the power-law portion of the data. It is also important to note that measurement error will likely cluster the small changes into a single category again resulting in a simple power-law distribution.

The distribution derived from the cusp catastrophe raises important questions about the nature of complexity in population dynamics. Although a false dichotomy is entrenched in ecological literature regarding density-dependent and densityindependent regulation of population dynamics, this distribution implies that both exogenous and endogenous factors can produce qualitatively similar dynamics. Given limited time series data, it is not clear which model is most parsimonious. Of course, the complexity of the rangeland ecosystem does not preclude the condition that both dynamical processes may be functioning in the system. Exogenous forces may drive the endogenous dynamics so that it is not the case of either/or but rather of both.

\section{A SIMPLE MODEL OF DENSITY- DEPENDENT AND INDEPENDENT PROCESSES}

We constructed a simple lattice-based model of grasshopper populations to demonstrate that a density-dependent dispersal model can account for spatial patterns that are similar to those seen in Wyoming outbreaks (see supplemental material) and yield a power-law signal indistinguishable from the time series of rangeland grasshopper populations from both Wyoming and Idaho.

Consider a lattice in which every cell has a critical threshold but that threshold is randomly determined for each cell. This differs from the SOC models in which the threshold is constant throughout the lattice. Ecologically, this threshold is the "carrying capacity" for that cell. The population of grasshoppers is distributed among the cells at values less than or equal to each cell's threshold. These values remain constant unless a perturbation occurs. Cells that contain populations lower than their thresholds are assumed to be held in check by density-independent factors (e.g., disease) or other elements of the complex food web of the rangeland. A slow forcing function is introduced that adds a single element to a random cell. The element can be considered a single grasshopper or some scaled number of grasshoppers. If the threshold is exceeded, rather than introduce density-dependent mortality on the cell, which would mimic the artificial dynamics of caged experiments, we allow the individuals of the cell to disperse. The dispersers are randomly distributed to the neighboring cells.

If a cell has been evacuated and the cascade causes dispersers to enter that empty cell these individuals are lost, under the assumption that the prior inhabitants consumed the forage in the cell before migrating. Thus, density-dependent mortality can occur, but it must be coupled with dispersal.

The set of rules includes several important biological factors that are generally absent in unstructured models. More realism as additional rules to the lattice dynamics could be included, but we start with the simplest set of rules that broadly captures the ecological dynamics.

The resulting dynamics are presented as a spatial time series (see supplemental material) and as a frequency distribution (Fig. 4). The spatial time series shows patterns that are qualitatively similar to the Wyoming spatial data (see supplemental material). It is important to note that the model can produce only single outbreaks at a time due to the disturbance regime. The multiple outbreaks in the Wyoming data imply that the model will need to be adjusted to include the possibility of multiple disturbances at a single time step. The model produces patterns similar to the standard sandpile model. Although these spatial patterns are fractal, the Wyoming data are at a resolution insufficient to determine if the geometry of the outbreaks is indeed fractal.

The frequency distribution (Fig. 4) of the model clearly demonstrates a power-law relationship that is akin to both the sandpile model and the data 
Fig. 4. The frequency distribution of the size of outbreaks from the population model over 50000 iterations.

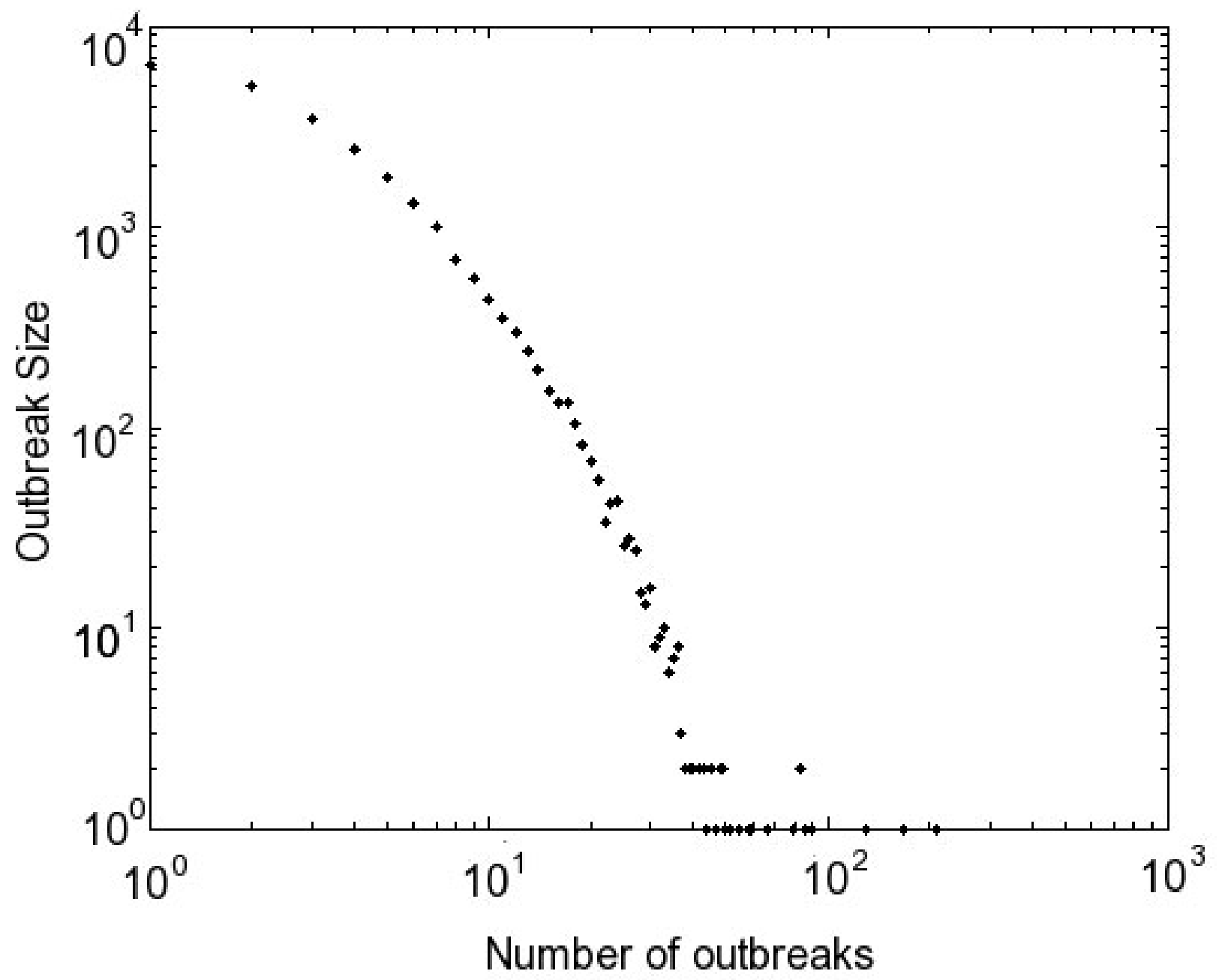

collected from rangeland systems. A variety of systems can produce $1 / f$ distributions (Pascual and Guichard 2005), but this simple model demonstrates that incorporating some of the basic biological processes with a spatial structure results in patterns similar to the spatial time series and the frequency distribution of the outbreak sequence.

\section{DISCUSSION}

Evidence for simple linear models to accurately produce dynamics that adequately describe grasshopper populations is completely lacking. The frequency distribution of the outbreaks points dramatically to nonlinear processes. Although 
delayed density dependence can create oscillations and simple discrete logistic models can create chaos, the time series data for grasshoppers demonstrate that these descriptions are insufficient to capture the observed dynamics.

The theoretical constructs that capture much of the qualitative behavior of outbreaks suggest that precise predictions, even in the short term, are highly unlikely. More work is necessary to improve the testing of such models against data, and this work must be informed by both theory and empirical studies. An active and constructively critical dialog between field researchers and modelers appears to have the greatest potential for generating useful solutions.

The food web presented in this paper hints at the complexity of the rangeland ecosystem, but it is incomplete. Most grasshopper species are generalists and the extent of their diets remains unknown. Even specialist species usually feed within a genus rather than being coupled tightly to a single species. Importantly, relevant ecological studies of the natural history of predators, parasites, and pathogens have virtually stalled. The best source for information regarding these organisms is over 40 years old, and the grasshopper species about which we have the greatest amount of data is $M$. spretus, which went extinct over a century ago. Without extensive natural history data, the ability to parameterize models remains insufficient to provide valuable tests for the theoretical studies.

Theory also suffers from strong dichotomous viewpoints. For too long has the debate of endogenous vs. exogenous regulation stymied successful theoretical insights into outbreak dynamics. Clearly, any population must ultimately be limited by density-dependent factors, if for no other reason than all habitats are finite in size and all organisms occupy non-zero space. But there is no evidence to suggest that density-independent process cannot dominate population dynamics over extended time scales. Berryman (1987) presents a model that is very similar to the cusp catastrophe, and he even points out that, as the environment shifts the parameters of the model, the equilibrium shifts from multiple stable states to a single value determined by the parameter. It is clear that the model is of the form of an equilibrium determined by the state of the population (endogenous control), which is a function of the environmental variation that influences the parameter space (exogenous control). This is, of course, exactly the same relationship provided by the cusp catastrophe. Likewise, Belovsky and Slade (1995) argue for density dependence, yet point out both that this value is a function of the environment and that densities are tied to weather. Again exogenous processes operate to constrain the endogenous process occurring in the experimental treatment. Thus, the question is not, "Which process is 'right' or has absolute primacy?" but, "How do the processes interact and under what conditions does a particular model yield useful information?"

As we show with a simple lattice-based model, a small exogenous forcing function coupled with density-dependent movement can provide qualitative and quantitative dynamics strikingly similar to actual data. This finding exemplifies the potential for conceptual approaches to theory choice in ecology that are both instrumentalist (treating theories as tools for problem solving, rather than as metaphysical commitments to the way the world "really is") and pluralistic (open to the possibility of perspectivism in which concepts can be cast in terms of "both A and B," rather than "either A or B"). As such, the choice of an analytical or explanatory method becomes a problem of contingency-knowing under what conditions a concept applies - rather than absolutism. This approach to solving ecological problems is functionally aligned with the philosophy of pragmatism. The right model to address a problem is a function of how we have chosen to frame the situation and whether the model provides a result (understanding, prediction, or control) that accords with the cultural, social, political, economic, ethical, or aesthetic outcomes that we desire.

In the case of our attempts to model the population dynamics of rangeland grasshoppers, we have selfconsciously sought tools that provide pest managers with forecasts (e.g., the cusp catastrophe) and insights (e.g., SOC). These results were intended to support managers in their efforts to both allocate resources (e.g., survey personnel, insecticides, and application equipment) and understand the ecological limitations of the system (e.g., local dynamics may not be tractable and interventions may function to spatiotemporally shift, rather than eliminate, infestations). To refine future forecasting efforts, field data on grasshopper densities should be collected with regard to taxonomy. Although it would be impractical to collect data for each species, at the very least the population densities of the major 
pest outbreak species should be differentiated from that of the non-pest species. Within the 10-15 pest species, data on each might well be within the capabilities of the surveying agencies. In the course of these pragmatically driven developments, important insights with respect to the dynamics of complex systems have emerged, which is something of a reversal of the traditional view that basic research gives rise to applied science.

\section{SUPPLEMENTAL MATERIAL}

The dynamics of grasshopper populations have large spatial structure and a temporal span of many years. Single synoptic maps of outbreaks (e.g., Schell and Lockwood, 1997) capture only a small representation of the processes. To better explore the dynamics, we constructed movies of the outbreaks and the model that allow a visual comparison of the dynamical processes that offer a perspective different from any single statistic or metric that could be applied to the spatiotemporal series.

The first movie (Appendix 1) illustrates the areas in Wyoming that experience outbreaks on an annual temporal scale. Each outbreak region, shaded in pink, represents the area of infestation at more than eight individuals per square yard. The boundaries on the map denote the counties of the state.

The second movie (Appendix 2) captures 50 iterations of the population model. Areas colored in pink are those that are above the threshold for their location for that iteration. The lattice grid is $100 \mathrm{x}$ 100 , with absorbing boundary conditions.

Responses to this article can be read online at:

http://www.ecologyandsociety.org/voll3/iss1/art34/responses/

\section{Acknowledgments:}

DRL was supported by NSF grant DGE-0221595 and the USDA-ARS. We would like to thank the two anonymous reviewers for their constructive comments.

\section{LITERATURE CITED}

Andrewartha, H. G., and L. C. Birch. 1954. The distribution and abundance of animals. University of Chicago Press, Chicago, Illinois, USA.

Arjo, W., and D. H. Pletscher. 1999. Behavioral responses of coyotes to wolf recolonization in northwestern Montana. Canadian Journal of Zoology 77(12):1919-1927. [online] URL: http://ar ticle.pubs.nrc-cnrc.gc.ca/ppv/RPViewDoc? handler = HandleInitialGet\&journal=cjz\&volume $=77 \&$ calyLang $=$ eng\&articleFile=z99-177.pdf.

Banfield, A. W. F. 1974. The mammals of Canada. University of Toronto Press, Toronto, Ontario, Canada.

Bekoff, M. 1977. Canis latrans. Mammal Species 79:1-9.

Belovsky, G. E., and J. B. Slade. 1995. Dynamics of two Montana grasshopper populations: relationships among weather, food abundance and intraspecific competition. Oecologia 101:383-396.

Berryman, A. A. 1987. The theory and classification of outbreaks, Pages 3-30 in P. Barbosa and J. C. Schultz, editors. Insect outbreaks. Academic Press, San Diego, California, USA.

Branson, D. H. 2005. Effects of fire on grasshopper assemblages in a northern mixed-grass prairie. Environmental Entomology 34(5):1109-1113. [online] URL: http://www.bioone.org/perlserv/?request= get-document $\&$ doi $=10.1603 \% 2 \mathrm{~F} 0046-225 \mathrm{X} \% 282005 \%$ 29034\%5B1109\%3AEOFOGA\%5D2.0.CO\%3B2

Capinera, J. L., and D. H. Horton. 1989. Geographic variation in effects of weather on grasshopper infestation. Environmental Entomology 18:8-14.

Capinera, J. L., R. D. Scott, and T. J. Walker. 2005. Field guide to grasshoppers, katydids, and crickets of the United States. Cornell University Press, Ithaca, New York, USA.

Capinera, J. L., and T. S. Sechrist. 1982. Grasshoppers (Acrididae) of Colorado: identification, biology, and management. Colorado State University Experiment Station Bulletin 584S, Fort Collins, Colorado, USA. 
Chapman, R. F. 1990. Food selection. Pages 2972 in R. F. Chapman and A. Joern, editors. Biology of grasshoppers. Wiley, New York, New York, USA.

Cuddington, K. M., and P. Yodzis. 1999. Black noise and population persistence. Proceedings of the Royal Society London B 266:969-973.

Edwards, R. L. 1960. Relationship between grasshopper abundance and weather conditions in Saskatchewan, 1930-1958. The Canadian Entomologist 92:619-624.

Edwards, R. L. 1962. A critical appraisal of grasshopper forecasting maps in Saskatchewan, 1936-1958. Journal of Economic Entomology 55:288-292.

Fielding, D. J., and M. A. Brusven. 1990. Historical analysis of grasshopper (Orthoptera: Acrididae) population responses to climate in southern Idaho, 1950-1980. Environmental Entomology 19(6):1786-1791.

Gage, S. H., and M. K. Mukerji. 1976. A predictive model for seasonal occurrence of three grasshopper species in Saskatchewan (Orthoptera: acrididae). The Canadian Entomologist 108:245253.

Gage, S. H., and M. K. Mukerji. 1977. A perspective of grasshopper population distribution of Saskatchewan and interrelationships with weather. Environmental Entomology 80:469-479.

Gilmore, R. 1981. Catastrophe theory for scientist and engineers. Wiley, New York, New York, USA.

Hall, C.A.S. 1988. An assessment of several of the historically most influential theoretical models used in ecology and of the data provided in their support. Ecological Modelling 43:5-31.

Hewitt, G. B., and J. A. Onsager. 1983. Control of grasshoppers on rangeland in the United States-a perspective. Journal of Range Management 36:202-207.

Joern, A., and S. B. Gaines. 1990. Population dynamics and regulation in grasshoppers. Pages 415-482 in R. F. Chapman and A. Joern, editors. Biology of grasshoppers. Wiley, New York, New York, USA.
Karpakakunjaram, V., M. D. Kolatkar, and M. C. Muralirangan. 2002. Effects of abiotic factors on the population of an acridid grasshopper, Diabolocatantops pinguis (Orthoptera: Acrididae) at two sites in southern India: a three-year study. Journal of Orthoptera Research 11(1):55-62. [online] URL: http://www.bioone.org/perlserv/?request= get-abstract\&issn $=1082-6467 \&$ volume $=011 \&$ issue $=01 \&$ page $=0055$.

Kemp, W. P., S. J. Harvey, and K. M. O'Neill. 1990. Patterns of vegetation and grasshopper community composition. Oecologia 83:299-308.

LaChapelle, A., F. Messier, and M. Crete. 1984. Importance of moose as a black bear food in southwest Quebec. Alces 20:79-83.

Lavigne, R. J., and R. E. Pfadt. 1966. Parasites and predators of Wyoming rangeland grasshoppers. Monograph 3. University of Wyoming and Wyoming Agricultural Experiment Station, Laramie, Wyoming, USA.

Lockwood, J. A. 1990a. Rangeland grasshopper ecology. Pages 83-102 in S. K. Gangwere, M. C. Muralirangan, and M. Muralirangan, editors. The bionomics of grasshoppers, katydids and their kin. CAB International, Wallingford, UK.

Lockwood, J. A. 1990b. Grasshopper population dynamics: a prairie perspective. Pages 103-127 in S. K. Gangwere, M. C. Muralirangan, and M. Muralirangan, editors. The bionomics of grasshoppers, katydids and their kin. CAB International, Wallingford, UK.

Lockwood, J. A., R. Anderson-Sprecher, and S. P. Schell. 2002. When less is more: optimization of reduced agent-area treatments (RAAT) for management of rangeland grasshoppers. Crop Protection 21:551-562. [online] URL: http://dx.doi. org/10.1016/S0261-2194(01)00145-4.

Lockwood, D. R., and J. A. Lockwood. 1989. Application of catastrophe theory to population dynamics of rangeland grasshoppers. Pages 268277 in L. L. McDonald, B. F. Manly, and J. A. Lockwood, editors. Estimation and analysis of insect populations. Springer Verlag, New York, New York, USA.

Lockwood, D. R., and J. A. Lockwood. 1997. Evidence of self-organized criticality in insect 
populations. Complexity 2:49-58.

Lockwood, J. A., and D. R. Lockwood. 1991. Rangeland grasshopper (Orthoptera: Acrididae) population dynamics: insights from catastrophe theory. Environmental Entomology 20:970-980.

Lockwood, J. A., and D. R. Lockwood. 1993. Catastrophe management: a unified paradigm for rangeland ecosystem dynamics. Journal of Range Management 46: 282-288. (online) URL: http://ww w.jstor.org/pss/4002459.

Lockwood, J.A., and S. P. Schell. 1995. Rangeland grasshopper outbreak dynamics: gradient, eruptive, both, or neither? Journal of Orthoptera Research 4:35-48.

Mandelbrot, B. B., and J. R. Wallis. 1969. Some long-run properties of geophysical records. Water Resources Research 5:321-340.

Morales, J. M. 1999. Viability in a pink environment: why "white noise" models can be dangerous. Ecology Letters 2:228-232. [online] URL: http://dx.doi.org/10.1046/j.1461-0248.1999.00074. $\underline{\mathrm{X}}$.

Narisu, J. A. Lockwood, and S. P. Schell. 1999. A novel mark-recapture technique and its application to monitoring the direction and distance of local movements of rangeland grasshoppers (Orthoptera: Acrididae) in the context of pest management. Journal of Applied Ecology 36:604-617. [online] URL: http://dx.doi.org/10.1046/j.1365-2664.1999.00421. $\underline{\mathrm{X}}$.

Pascual, M., and F. Guichard. 2005. Criticality and disturbance in spatial ecological systems. Trends in Ecology and Evolution 20(2):88-95. [online] URL: http://dx.doi.org/10.1016/j.tree.2004 .11 .012 .

Pelletier, J. D. 1997. Analysis and modeling of the natural variability of climate. Journal of Climate 10:1331-1342.

Peterson, R .L. 1955. North American moose. University of Toronto Press, Toronto, Ontario, Canada.

Pfadt, R. E. 2002. Field guide to the common western grasshoppers. Third edition. Wyoming Agricultural Experiment Station Bulletin 912, Laramie, Wyoming, USA.
Pierce, D. J., and J. M. Peek. 1984. Moose habitat use and selection patterns in north-central Idaho. Journal of Wildlife Management 48(4):1335-1343.

Price, P. W., and K. M. Clancy. 1986. Multiple effects of precipitation on Salix lasiolepis and populations of the stem-galling sawfly, Eurara lasiolepis. Ecology Research 1:1-14.

Ritchie, B. W. 1978. Ecology of moose in Fremont County, Idaho. Wildlife Bulletin No. 7, Idaho Department of Fish and Game, Boise, Idaho, USA.

Schell, S. P., and A. V. Latchininsky. 2006. Grasshoppers of Wyoming and the West. [online] URL: http://www.sdvc.uwyo.edu/grasshopper/ghwywfrm. htm.

Schell, S. P., and J. A. Lockwood. 1997. Spatial analysis of ecological factors related to grasshopper population dynamics in Wyoming. Environmental Entomology 26:1343-1353.

Skinner, K. M., and R. D. Child. 2000. Multivariate analysis of the factors influencing changes in Colorado grasshopper abundances. Journal of Orthoptera Research 9:103-109.

Streett, D. A., and M. R. McGuire. 1990. Pathogenic diseases of grasshoppers. Pages 483 516 in R. F. Chapman and A. Joern, editors. Biology of grasshoppers. Wiley, New York, New York, USA.

Swetnam, T. W., and A. M. Lynch. 1993. Multicentury, regional-scale patterns of western spruce budworm outbreaks. Ecological Monographs 63(4):399-424.

Thom, R. 1972. Structural stability and morphogenesis. (English translation, D.H. Fowler, 1975.) Addison Wesley, Reading, Massachusetts, USA.

Turchin, P. 1995. Population regulation: old arguments and a new synthesis. Pages 19-42 in N. Cappuccino, editor. Population dynamics. Academic Press, San Diego, California, USA.

Watts, J. G., E. W. Huddleston, and J. L. Capinera. 1982. Rangeland entomology. Annual Review of Entomology 27:283-311.

Vattay, G., and A. Harnos. 1994. Scaling behavior 
in daily air humidity fluctuations. Physical Review Letters 73:768-771.

Ylioja, T., H. Roininen, M. P. Ayres, M. Rousi, and P. W. Price. 1999. Host-driven population dynamics in an herbivorous insect. Proceedings of the National Academy of Sciences U.S.A. 96 (19):10735-10740. [online] URL: http://www.pnas. org/cgi/content/full/96/19/10735. 
Appendix 1. The movie illustrates the areas in Wyoming that experience outbreaks on an annual temporal scale. Each outbreak region, shaded in pink, represents the area of infestation at $>8$ individuals per square yard. The boundaries on the map denote the counties of the state. (File size: $7184.9 \mathrm{~KB}$, File type: Windows Media Video File, View with: Windows Media Player)

Please click here to download file 'appendixl.wmv'. 
Appendix 2. The movie captures 50 iterations of the population model. Areas colored in pink are those that are above the threshold for their location for that iteration. The lattice grid is 100x100 with absorbing boundary conditions. (File size: 1023.7 KB, File type: Windows Media Video File, View with: Windows Media Player)

Please click here to download file 'appendix2.wmv'. 